\title{
Therapeutic or Diagnostic Output Failure
}

National Cancer Institute

\section{Source}

National Cancer Institute. Therapeutic or Diagnostic Output Failure. NCI Thesaurus. Code C62828.

Problem associated with the failure of the device to deliver the output required for treatment or identification of a disease. 